\title{
RAF Newton: A case study for investigating why certain historic sites are preserved
}

Received (in revised form): 2nd September, 2008

\begin{abstract}
Simon Mclean BSc Hons, MA, PGCE, MRICS
is a chartered building surveyor and an associate director of a building surveying practice. He teaches practical building surveying in the School of Construction, Cost and Surveying at Sheffield Hallam University. Having an ex-RAF airman father meant that he was brought up knowing about life as a wartime aviator. His interest in historic buildings has been lifelong, but was focused by studying for a master's degree in Conservation of Historic Buildings at the Institute of Advanced Architectural Studies at the University of York. Further academic and practice activity has strengthened his love of historic buildings and their conservation, and it was leading student field work which first led him in to the gates of the former RAF Newton.
\end{abstract}

Correspondence: Simon Mclean, Sheffield Hallam University, 40 Milton Drive, Ravenshead, Nottinghamshire NG15 9BE, UK; Tel: +44115848 2562;

E-mail: s.n.mclean@shu.ac.uk

\begin{abstract}
The redundant airbase at RAF Newton in Nottinghamshire saw action as a bomber base and still retains its contemporary World War II (WWII) buildings, although many are suffering dilapidation. Since it closed as a working RAF base in 2000, a number of mostly residential-based development proposals have been brokered for the site. The author using the example of RAF Newton and two other RAF bases, which have been preserved as RAF museums, namely Duxford in Cambridgeshire and East Kirkby in Lincolnshire looks to establish why the latter two flourish as preserved bases while the apparently more complete, more compact and the base which it could be argued possesses the more original landscape looks likely to disappear. RAF Newton is tested under the articles of the Burra Charter to see if the prerequisite for conservation, 'cultural significance' can be established. The physical presence of Newton is tested against stated English Heritage guidelines over what constitutes an ideal WWII aviation heritage site. Finally the preservation of sites like RAF Newton is tested using the terms of the latest Nottinghamshire Local Plan, to establish if there is a desire within planning policy to conserve such sites over straight development proposals. While it appeared that RAF Newton could be conserved as a WWII heritage site, the reason why it might not follow Duxford and East Kirkby as such might be found outside of philosophy, and written guidelines.

Journal of Building Appraisal (2008) 4, 115-124. doi:10.1057/jba.2008.32
\end{abstract}

\section{Keywords:}

conservation, development, cultural significance, Burra Charter, local development plan, statutory protection

\section{INTRODUCTION}

The author was fortunate to gain access to the ex-RAF airbase at Newton in Nottinghamshire. The base was decommissioned as a working airbase in 1990. Having visited other such bases, like East Kirkby in Lincolnshire and Duxford in Cambridgeshire, the author saw that this base in comparison appeared to be quite complete. Its main 
buildings appeared contemporary with its pre-World War II (WWII), build date. The main site contained five large aircraft hangers, a number of administrational and operational buildings, a control tower, fuel store, arms store, guard house, gate house, transport depot, fire tender station, and grass runway. There was even an existing outer marker building left over from the use of the runway. Additionally in a separate location within the site, there was a further later RAF development of recreation buildings, education block, married quarters, and mess buildings. The site straddled green belt designation, with the principle landowner in a three-way ownership being the Crown. The part of the site where most of the WWII buildings are located was acquired by a developer in 2004.

Since its closure as an airbase in 1990, a number of schemes for usage of the site have been proposed. These include a doomed plan to use it to house asylum seekers, a housing development requiring exchange of land from and to the greenbelt register, and the currently under consideration plan, but looking an increasingly unlikely proposal, for creating a new eco-town of 5,000 plus houses and supporting infrastructure (Figure 1). While its future is decided, the large hangers and some office spaces are being leased for industrial purposes, as they have been for some years and the other buildings remain mostly redundant. Cited issues that have impacted upon the suitability of the various schemes proposed have included the views of the residents of the nearby village of Newton to traffic type and volume and the consequences of being neighbours to an asylum seekers centre. Potential traffic and vehicular access ingressing and egressing the A46 road that boarders the site, and the town of Bingham has caused more general issues, as has use of greenbelt land, and the impact of any large-scale development upon the infrastructure and character of the small rural town of Bingham. In a long search of proposed uses, however, no serious mention of the base as being a site of historic and cultural importance and therefore worthy of preservation as a complete working WWII

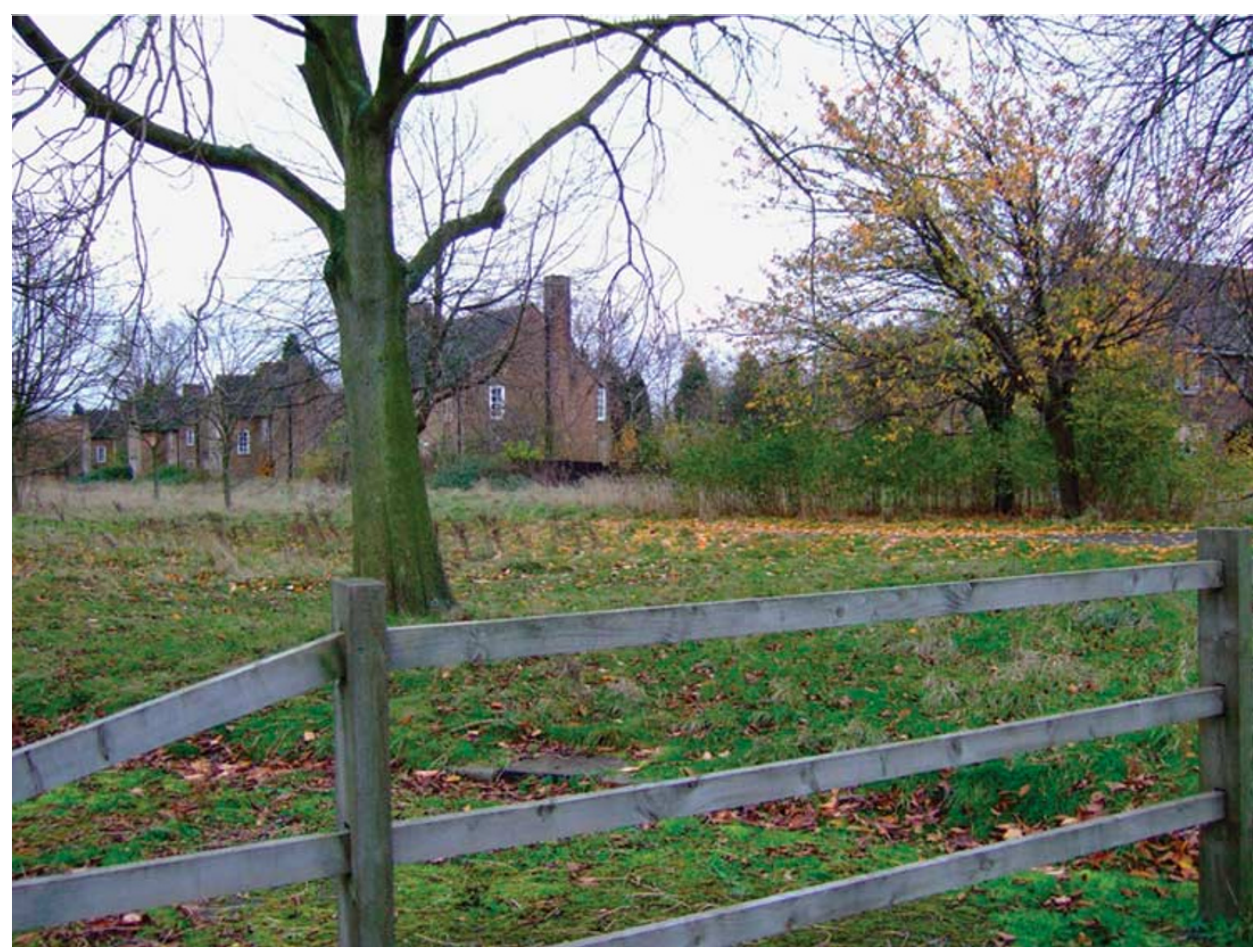

Figure I: View from the south of the site, note the level plot with rural aspect, so prized by house builders 
airbase was noted by the author. This led the author to look at the site in terms of current conservation philosophy, the stated aims and philosophy of English Heritage (EH), in respect of the quality of military bases and air bases in particular, current planning policy guidance (PPG15, PPG16), and the latest Nottinghamshire Local Development Plan, to see why it might be that the WWII RAF heritage at the less complete East Kirkby site or the less clearly defined Duxford site should have been preserved while it appears that at Newton it will not.

\section{HISTORY OF RAF NEWTON}

Built upon the site of an existing civil airfield, 7 miles south of Nottingham in 1939 RAF Newton was one of the last of about 100 expansion airbases to be built as a permanent base in response to the perceived military threat from mainland Europe in the 1930s. Airbases built after this time though more numerous tended to be temporary in nature, and consequentially few have survived at all and especially not in their complete form. RAF Newton is cited by EH (English Heritage 50563, 2003b), as being typical of the pre-hostilities construction, which was a simplistic functional architectural form and employed the use of industrialised materials such as brick and concrete. In comparison to widely spread out bases such as Duxford, Newton's WWII core was still a compact site.

RAF Newton was first assigned to 103 and 150 bomber squadrons on their return from France in June 1940, and was used as a base for Vickers Wellington Bombers until 1941, when it saw use as a training base for the 16 group Polish Service Flying Training School. This school provided basic and advanced pilot training for Polish pilots until 1946. From that date until 1958, it became the headquarters for 12 group fighter command. In later years it saw use as home of the RAF School of Education until its closure as a functioning RAF base in 2000. Latterly it saw use as a training base for both technical and air crew, and also for the RAF police force (Wikipedia, 2008).

After some debate about its future, part of the site was purchased by a developer in 2004; however, that future is still not totally decided. In the mean time those buildings which can easily be reused for commercial purposes are being leased as office and storage areas, while the civilian Police Armed Response and mounted units use the site for training. The three grass airstrips have reverted to pasture; however, its wartime archaeology reputedly has thus far been left untouched. Of the many WWII buildings present on the site, it was reported to the author that only one was listed. This was the control tower which was reported as being listed at grade 2; however, an extensive search by the author of the Nottinghamshire and Rushcliffe Listed Buildings Registers failed to find this listing (Figure 2). The listing or not of this individual structure is perhaps irrelevant in the context of saving the whole site as it sits aside crown land, which is exempt from listed building controls. Additionally at the time of the author's inspection, very little remained of the interior contents of the tower. Hence, the value of any cultural significance it might currently possess would be external. That significance would be rendered debatable should development remove its contemporary structures and were the grassed area that formed its runways, and could still afford access by aeroplane, to be developed. Part of the site is designated as being green belt land.

The author was unable to gain access to all the subject buildings or to undertake more than a cursory inspection; however, it was noted that although the period of redundancy has been relatively short, those buildings that have not found a tenant were showing strong signs of dilapidation. The 1930s in situ-concrete, clearly not the most durable mix, is showing signs of deterioration and water is ingressing some buildings. Those interiors 


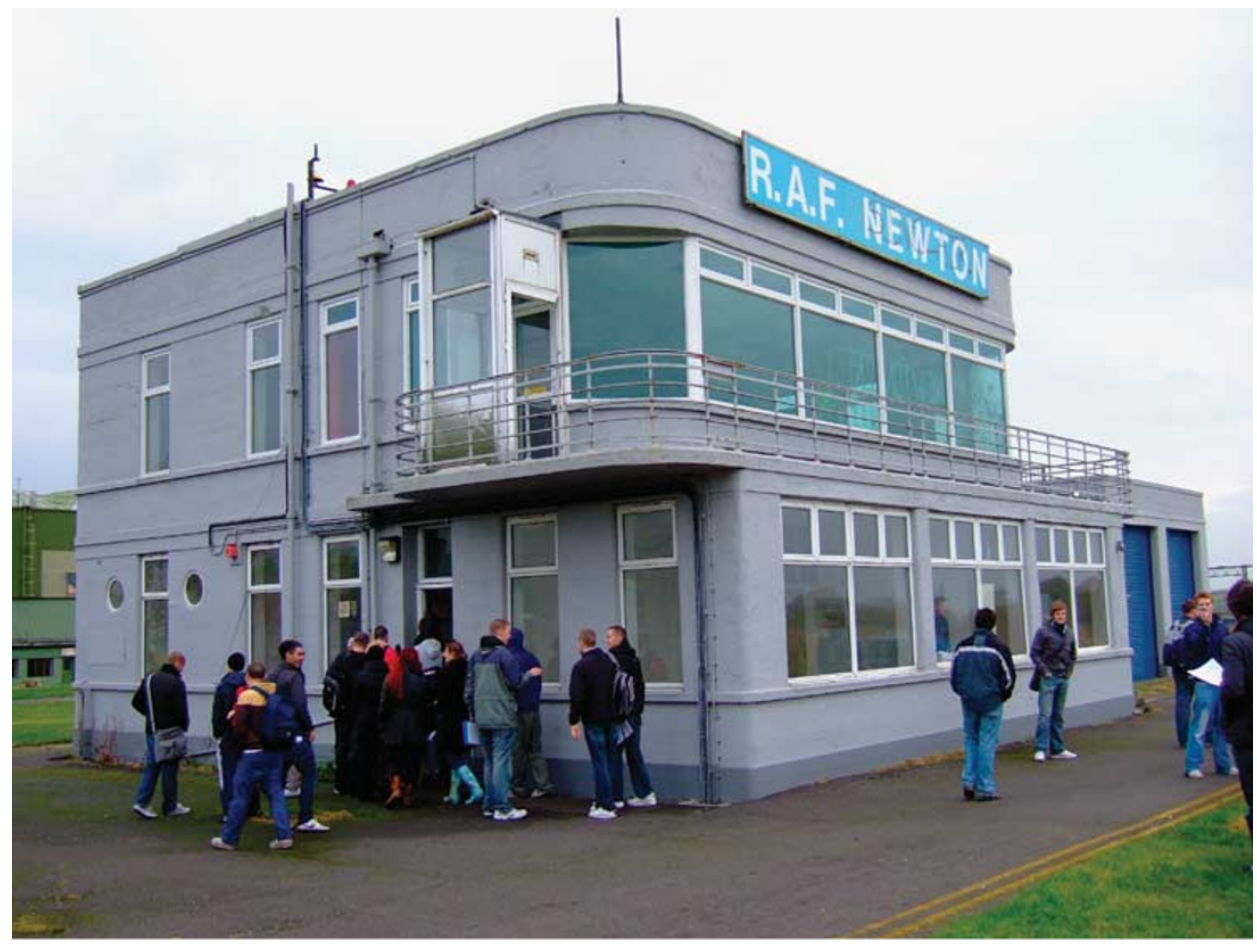

Figure 2: Control tower

that were possible to enter were generally in poor condition. The hangers and rented office space by contrast appear to be well maintained and in appropriate order (Figure 3). No major or even minor structural collapse was noted. The hard standing and track ways were in serviceable order and still contemporary with their airbase usage. Considerable numbers of heritage pieces from the airbase days like signage were still in situ (Figure 4). The site is clearly still preservable as a complete WWII airbase; however, further deterioration of any of the key buildings will quickly erode that possibility.

\section{ASSESSMENT OF POTENTIAL CULTURAL SIGNIFICANCE}

The source of current conservation philosophy is often cited as being the Burra Charter, as produced by the International Council on Monument and Sites, ICOMOS, following the international conference on conservation held at Burra Burra, Australia, in 1979. This charter underpins current philosophy in respect of conservation of historic buildings and sites, and evidence of its doctrine can be found within both PPG15 and PPG16, which are the guidance documents which planners should use when considering planning applications affecting listed buildings, conservation areas, or sites of potential archaeological interest. By using the main principles of that charter, that a building or site must be culturally significant to warrant preservation and that it is those factors which manifest the cultural significance which are those upon which conservation efforts should be directed, the author will seek to establish if there is a case for declaring RAF Newton as worthy of preservation. Article 2 of the Burra Charter defines four main categories for assessment of cultural significance. These are aesthetic value, historic value, scientific value and social value; however, it does concede that this in not exhaustive and other approaches may constitute cultural significance (Marquis Kyle and Walker, 1994). 


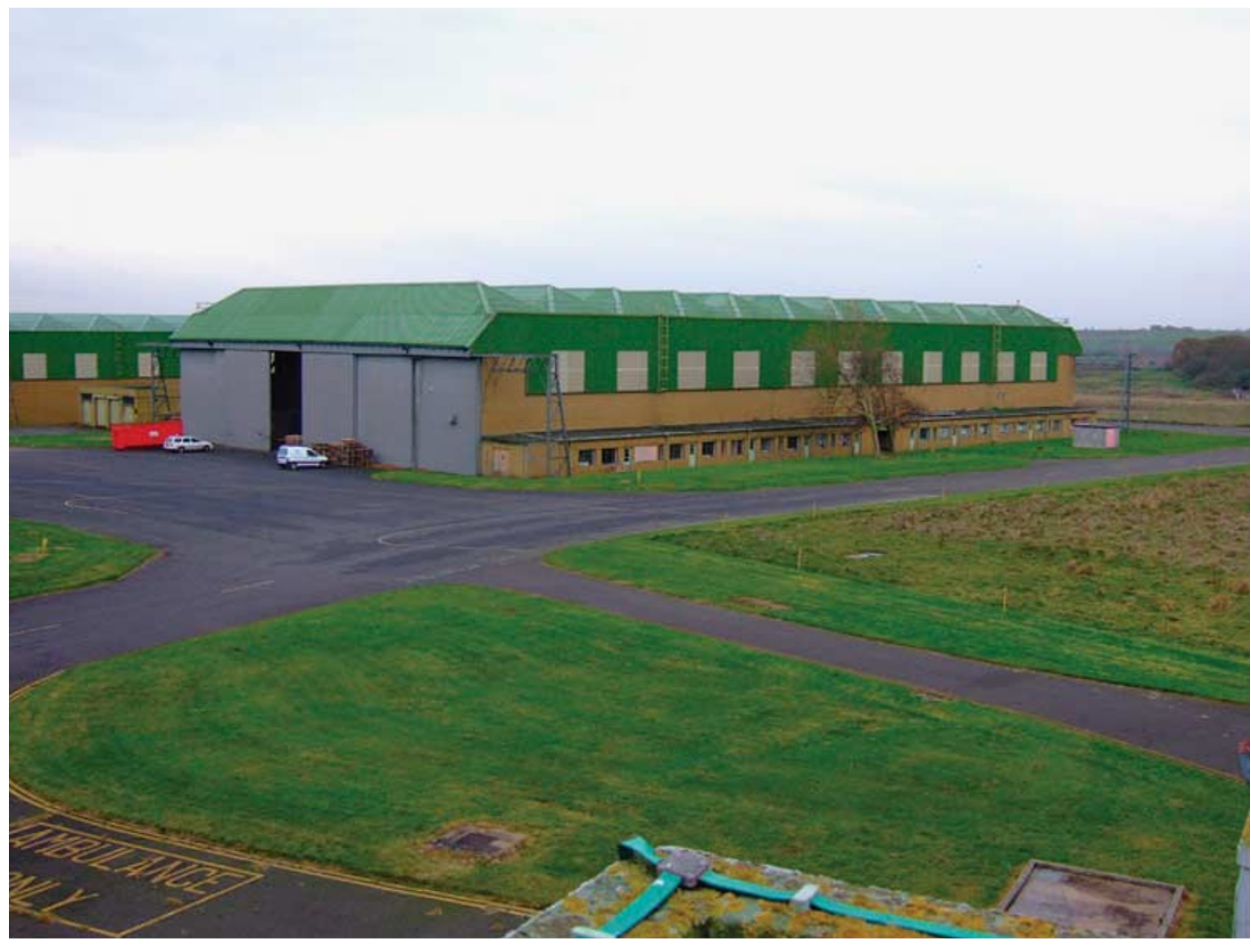

Figure 3: Example of the aircraft hangers

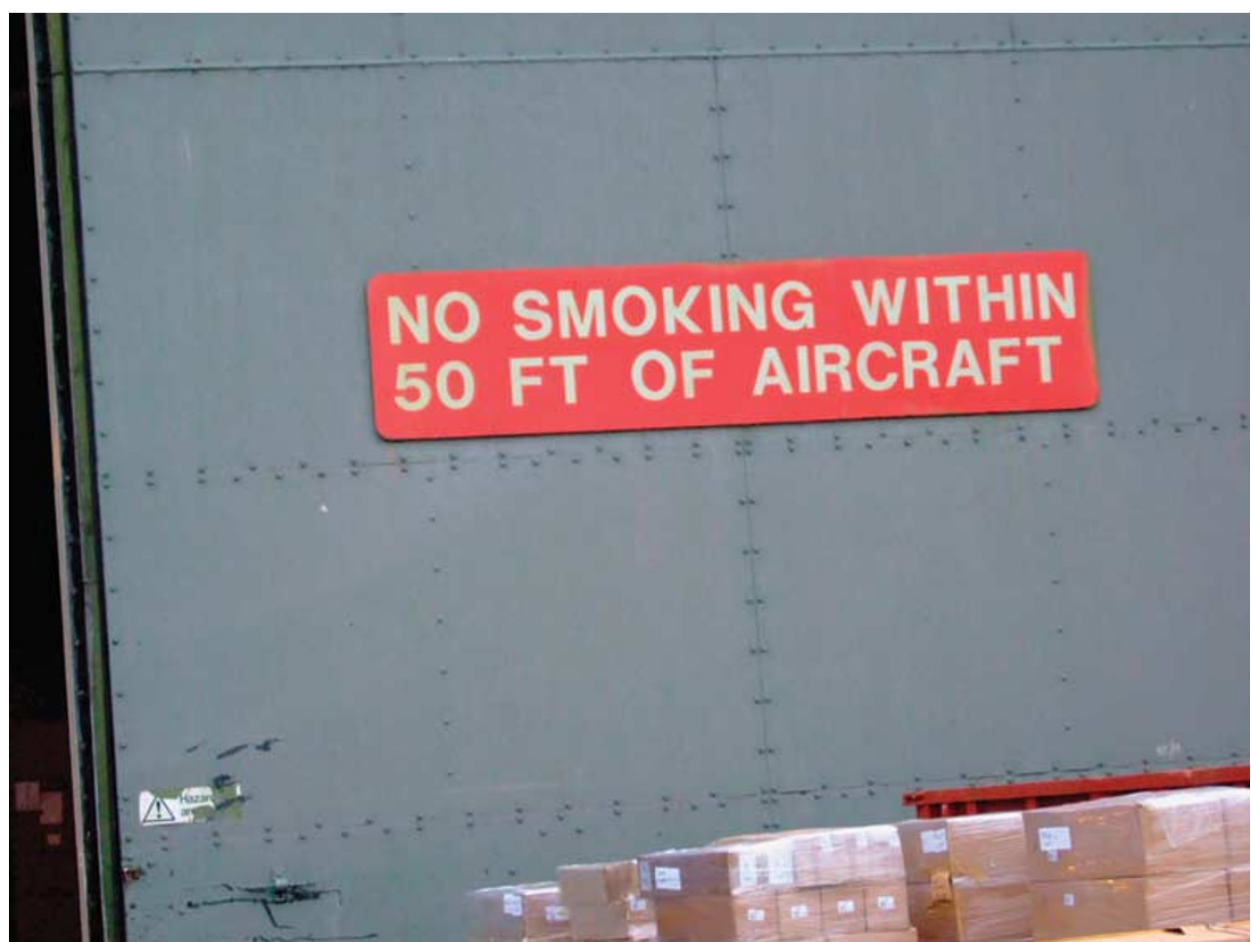

Figure 4: In situ signage 
Aesthetic value is cited by the charter as being 'aspects of sensory perception' (Marquis Kyle and Walker, 1994). These are said to include criteria of form, scale, colour, texture, material of the fabric and smells and sounds. To establish whether RAF Newton might meet the criteria of having aesthetic value as a WWII airbase, the author looked to the guardians of our historic built environment, EH for the defining characteristics for what might constitute a valuable heritage rich WWII airbase. In their guidance booklet Historic Military Aviation Sites Conservation Management Guidance (English Heritage 50771, 2003a), any surviving expansion airfield was cited as being one of only 100 such sites built, and many fewer than that still survive. It states that the site requires to have a remained open aspect with a generous provision of trees and grassed areas. This landscaping is cited as being a vital component and easily lost. The buildings are cited as being of simple form, built from materials such as concrete and brick, with a consistency of architectural form and texture throughout the site. The authentic base is cited as having a campus layout, which can easily be disrupted by later buildings and a special colour and texture, which again can be diluted by later additions, which utilise different materials and colours. The presence of contemporary signage and textures is also cited as important.

Given this description of the typical authentic WWII airbase, RAF Newton would appear to typify much of this. It is set amidst an open grassed landscape with mature trees. Its main base comprises buildings of brick and in situ-concrete construction. Its wartime defence features of flat roofs blast walling and earth banking around the armoury store still exists (Figure 5), and all later buildings were added to a distant part of the site, thus leaving its WWII ambience largely remaining unaffected (Figure 6).

Historic value is cited in the Burra Charter as being influencing historic figures or events or being the site of a historic event. This significance is considered greater if the site still evidences an association with the event (Marquis Kyle and Walker, 1994). In this

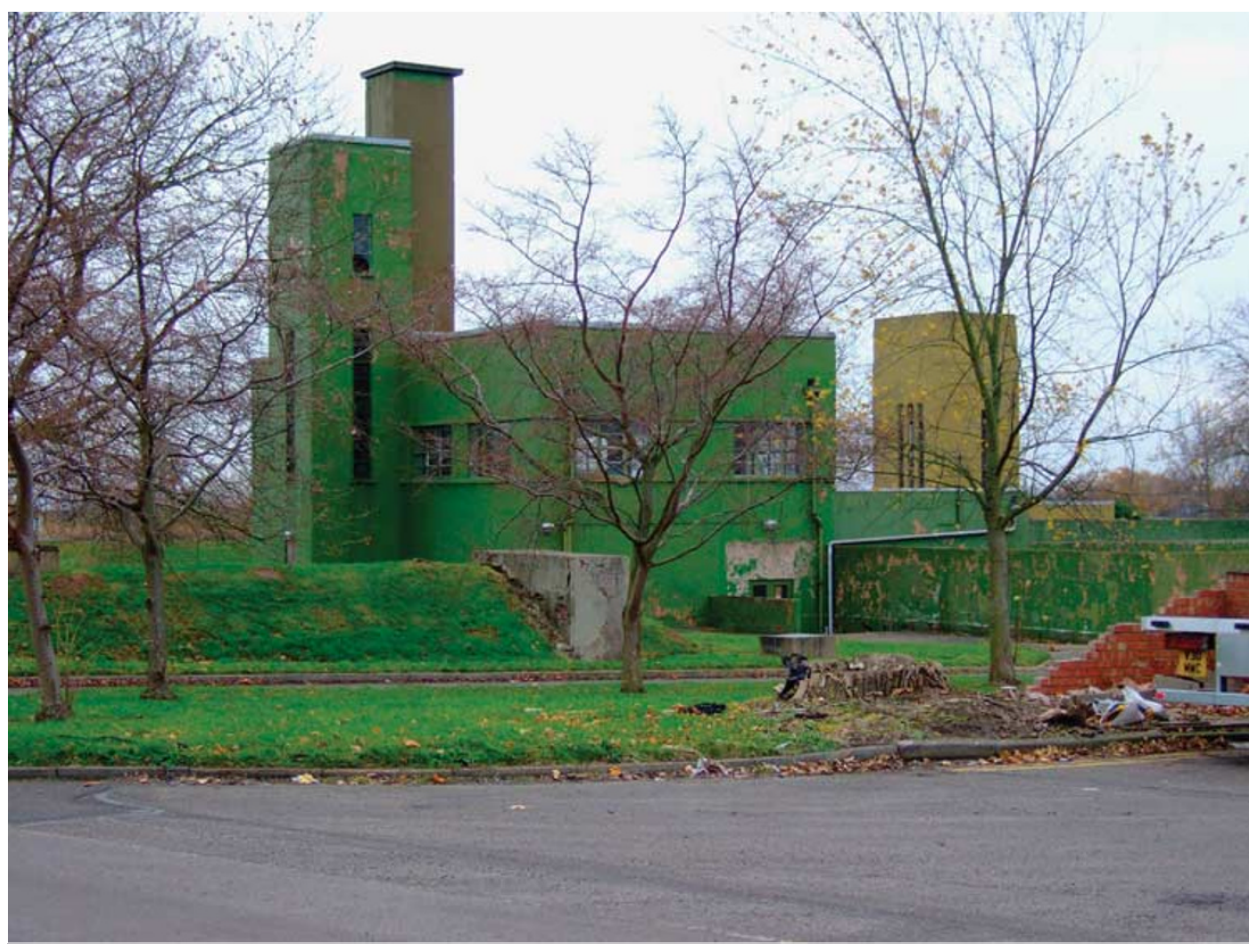

Figure 5: Blast protection and flat-roofed architecture for protection against incendiary bombs 


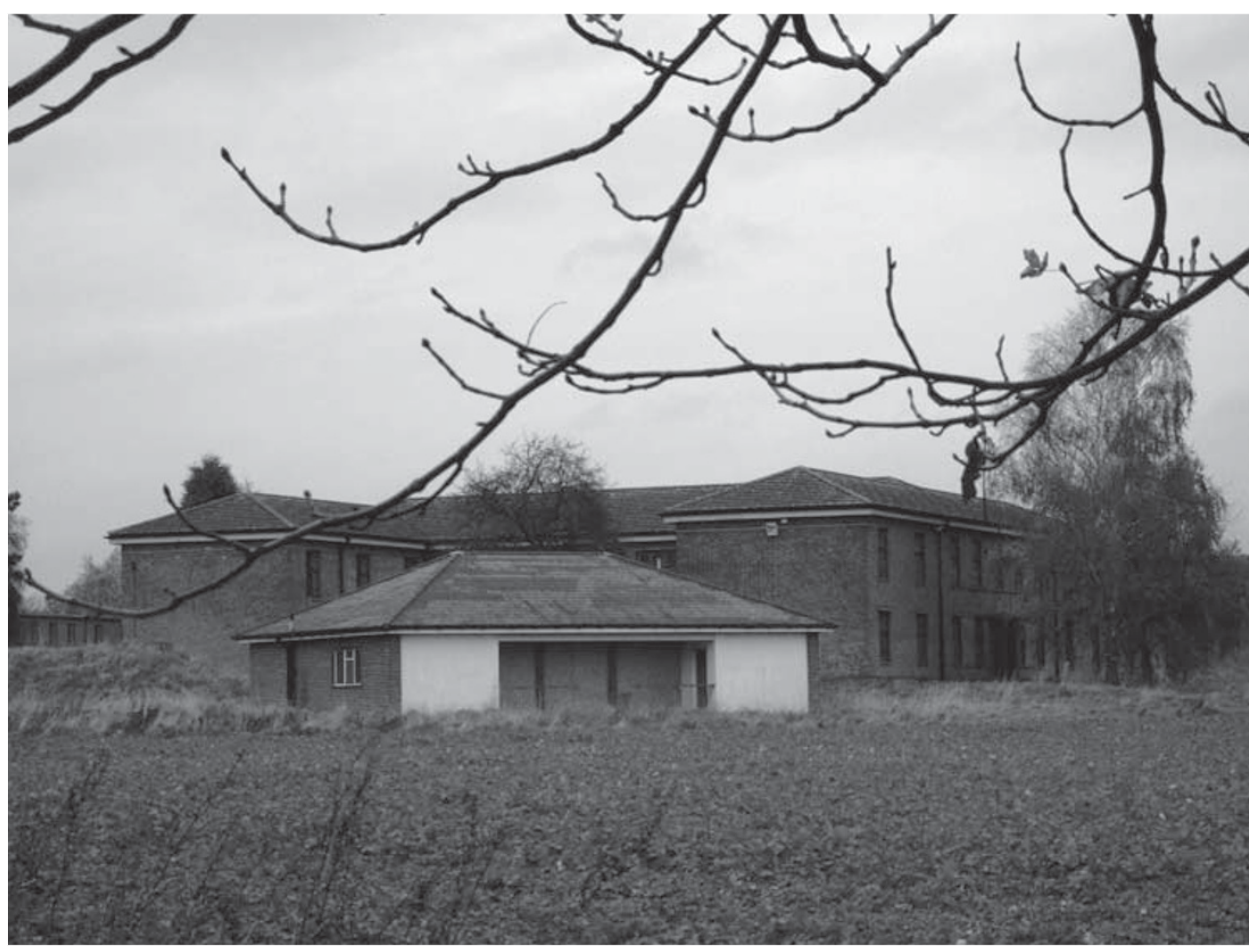

Figure 6: Later buildings of a differing architectural form, but fortunately on this site not impacting upon the WWII area

respect the event is WWII. With active bombing raids operating for only one year of the war, its significance in this respect falls behind both Duxford and East Kirkby. The author is unaware of any renowned aviators who first trained at Newton; however, the significance is heightened by the current site which still very much resembles the archetypical wartime airbase.

The author is unaware of any major archaeological work undertaken on the site to expose any wartime or earlier finds, and local tales of buried caches of munitions remain purely that. There is no firm available evidence to suggest that that any scientific data available from the site is likely to be unique or contribute significantly to current knowledge, although the area is renown for pre-historic activity and is close to the Roman Fosse Way (Nottinghamshire Joint Structure Plan).

Social value is cited as being qualities which render the place important for spiritual, political, national, or other social sentiment reasons to a majority or minority group (Marquis Kyle and Walker, 1994). Given that only a few ex-WWII airmen still live, direct links with the 1940s base will be few. As EH cited (English Heritage 50771, 2003a), however, this has largely been replaced in later generations by sentiment derived from the popularity of war films. In this context the history of RAF Newton could be perceived as less exciting than other similar frontline sites, like Duxford. RAF Newton, however, has strong links with the Polish squadrons, and there is a strong local link to the Polish participation in the war with a large Polish War Cemetery located in nearby Newark on Trent.

Given the criteria for establishing cultural significance, as cited in the Burra Charter any conservation assessment, as advocated by Article 3 of the Burra Charter (Marquis Kyle and Walker, 1994), could well find that the site has aesthetic cultural significance as a complete WWII airbase, EH cite completeness as pivotal in assessing the quality 
of a military site (English Heritage, 2003a, b), and social cultural significance to a minority group with strong wartime ties to the area. Additionally it might conclude that its wartime history while not the stuff of legend is still complete and valid. As there is a case under currently accepted conservation philosophy for extending the statutory protection to single buildings like the hangers and the control tower or to the whole of the site as a group, the author will appraise the specific wisdom of EH, general planning policy guidance instruction, and the specifics of the Nottinghamshire Local Plan to establish if reasons exist beyond purely economic ones why RAF Newton has not been considered for preservation as a WWII aviation heritage site.

\section{EH VIEWS ON WHAT CONSTITUTES A WARTIME SITE WHICH SHOULD BE CONSERVED}

EH produced its guidance leaflet 'Historic Military Airfields Conservation Management Guidelines' in June 2003. While it mostly cites general conservation issues and deals with issues specific to maintaining WWII airbase buildings, it does, however, make some significant points, in respect of whether a base should or should not be preserved. Unfortunately the thematic study of pre-1945 airfields delivered in 2000, would probably have excluded Newton as the WWII core of the base was at the time of survey part of a larger working airfield under Ministry of Defence control, and therefore outside of EHs. They did, however, note that 'comparatively few WWII airbases survive in recognisable form'. This makes the site at Newton currently significant by virtue of rarity, and its demolition a hard blow to the availability of such heritage. Vulnerability was cited as a particular problem for airbases. They were cited as being vulnerable to demolition, disrepair, subdivision of ownership, inappropriate development, and alteration of the landscape. In respect of the site at Newton disrepair may render some of the commercially unusable buildings beyond repair before final plans for the future of the site are settled. This given the value of having a complete set of buildings would have a dramatic impact upon the cultural significance of the site. One interesting point raised was the precedents which have been set at sites like RAF Manby in Lincolnshire, also an ex-training station, where management of the conservation of a near complete set of buildings is in place on a site which has an alternative commercial primary usage and is not currently in use as a heritage park.

\section{NOTTINGHAMSHIRE JOINT STRUCTURE PLAN (ADOPTED FEBRUARY 2006)}

Given that under the terms of the Burra Charter evidence of cultural significance can be found for the WWII buildings at RAF Newton, and when the completeness of the site is taken in to account, the fact that its open campus aspects remain and its rarity there would seem to be a strong argument for preservation of the WWII buildings at RAF Newton, either as a museum site or as with RAF Manby as part of an alternative overall site usage. It is very unlikely that any building or part of the site would gain a higher level of statutory protection than grade 2 or basic conservation area status which would take decision making on its future away from local authority control and in to that of EH. Consequentially, it seems prudent to establish how this site might be treated by that local authority by making reference to the current development local structure plan for Nottinghamshire, which is guided by the provisions of PPG15 and PPG16.

In policy $2 / 12$, the local authority set out their philosophy for preserving the historic character of Nottinghamshire. They start by stating:

'Local planning authorities will protect and enhance the historic and architectural character and appearance of the landscape of the plan area'. 
This would seem to favour preservation of RAF Newton which has rare architectural value, a unique character, and a strong but fragile landscape which has dominated the area for over 70 years. The local authorities have stated firm action points to achieve this preservation aim (Nottingham and Nottinghamshire Joint Structure Plan Explanatory Memorandum Adopted February 2006):

(a) the protection and maintenance of buildings listed as of special architectural historic or landscape importance, including their setting;

(b) the identification, protection, and maintenance of other individual and groups of buildings which are important, including their setting;

(c) the identification, maintenance, and enhancement of other locally distinctive and culturally important aspects of the historic environment;

(d) the designation, enhancement, and preservation of conservation areas and their settings;

(e) sensitively designed environmental improvement and traffic management;

(f) finding appropriate alternative uses for and the restoration of, listed or other buildings worthy of retention; and

(g) informed design of new developments.

Additionally the plan states that the protection of groups of buildings that are locally important in themselves or as contributors to the character of the local area needs to be considered at planning level. Historic buildings that are no longer required for their original use are nevertheless viewed as a key asset, and that once restored they can contribute to local regeneration.

It would appear that the Nottinghamshire local plan would favour the preservation of sites such as RAF Newton over their total redevelopment. A key statement in the plan however talks about the need for statutory protection in the form of listing, scheduled monument status, or conservation area status. It may be that prior legal protection may be required for the local planners to view RAF Newton as a heritage asset.

\section{CONCLUSION}

The author started this research to identify why the compact and apparently complete WWII airbase at RAF Newton faces destruction at the hands of developers while the less complete RAF East Kirkby and the fragmented base at Duxford are preserved. One reason might be the history. With the demise of those airmen who fought in WWII, the direct link has been replaced by sentiments gained by watching war films and archive footage. In that respect, the Lancaster Bomber history of East Kirkby and the Battle of Britain history of Duxford would seem stronger, than Newton's relationship with the lesser known Wellington Bomber and use as a training base. The guidelines issued by EH, however, would favour architectural style, completeness of the building set, and maintenance of the original landscape and layout as being the key factors in assessing a base for preservation.

Using the Burra Charter's definitions for establishing cultural significance and the apparent history, physical presence of the site, and links to a strong minority group, a good case for cultural significance and a need to conserve RAF Newton as a complete WWII airbase can be established. The difference between the three sites, however, might be that there is not the same degree of will for preservation at Newton. The local authorities have written comprehensive proposals for preserving valuable heritage, both 
built and landscaped within their joint structure plan, but it may be that prior statutory recognition of the site may be required for it to be considered for adoption of these proposed restrictions to any planning applications.

If RAF Newton is to gain recognition as a site worthy of preservation, it is not the developers who will drive the recognition process. In the recently published report (Newtonecotown, 2008) to support the proposal for building an eco-town, the developer's appraisal of heritage issues studiously ignored any of the site's WWII bomber history or any mention of its constituent parts, and even suggested that its proximity might compromise any cultural significance to be found in the nearby Newton village. Unless there is a popular will beyond the preservation of single special interest buildings, to push forward statutory protection and strive to retain this site as a memorial to WWII airbases, a site which to lovers of military history and in particular WWII aviation might find quite magical, it could like most other similar bases be lost for ever. Decedents of Polish airmen may find that all traces of their ancestors wartime activities might be now consigned only to photographs, letters, and reminiscences posted on the internet.

\section{References}

Department of the Environment. (1990) PPG16 Archaeology and Planning, HMSO, London, ISBN 0-11-752353-4. Department of the Environment. (1994) PPG15 Planning Policy Guidance Planning Policy and the Historic Environment, HMSO, London, ISBN 0-11-752044-3.

Development Strategy Document. (2008) An Eco-town at Former RAF Newton/Bingham, www.newtonecotown.com.

English Heritage. (2003a) Historic Military Aviation Sites Conservation Management Guidance, English Heritage Product Code 50771, Swindon.

English Heritage. (2003b) Twentieth Century Military Sites Current Approaches to their Recording and Conservation, English Heritage Product Code 50563, Swindon.

Marquis Kyle, P. and Walker, M. (1994) The Illustrated Burra Charter Making Good Decisions about the Care of Important Places, 2nd edn, Australia ICOMOS, Brisbane.

Nottinghamshire County Council. (2006) Nottinghamshire and Nottingham Joint Structure Plan, Chapter 2: Environment and Natural Resources, Explanatory Memorandum, NCC, West Bridgeford.

Wikipedia. (2008) RAF Newton, en.wikipedia.org/wiki/RAF_Newton. 